\title{
Risk Factors for Hepatitis C Virus (HCV) Infection in Areas with a High Prevalence of HCV in the Republic of Korea in 2013
}

\author{
Hae-Sook Sohn*, Jang Rak Kim ${ }^{\dagger}$, So Yeon Ryu ${ }^{\ddagger}$, Youn-Jae Lee ${ }^{\S}$, Myeong Jin Lee", Hyun Ju Min ${ }^{\natural}$, Jun Lee ${ }^{\#}$, Hwa Young \\ Choi**, Yeong Jun Song ${ }^{\text {t† }}$, and Moran $\mathrm{Ki} * *$ \\ "Department of Preventive Medicine, Inje University College of Medicine, Busan, ${ }^{\dagger}$ Department of Preventive Medicine, Gyeongsang National \\ University School of Medicine, Jinju, ${ }^{\ddagger}$ Department of Preventive Medicine, Chosun University Medical School, Gwangju, ${ }^{8}$ Department of \\ Internal Medicine, Inje University Busan Paik Hospital, Busan, "Department of Health and Medical Administration, Suncheon Jeil College, \\ Suncheon, "Department of Internal Medicine, Gyeongsang National University School of Medicine, Jinju, "Department of Internal Medicine, \\ Chosun University Medical School, Gwangju, **Department of Cancer Control and Policy, Graduate School of Cancer Science and Policy, \\ National Cancer Center, Goyang, and ${ }^{t+}$ Department of Preventive Medicine, College of Medicine, Eulji University, Daejeon, Korea
}

Background/Aims: The prevalence of hepatitis $\mathrm{C}$ virus (HCV) infection in Busan, Gyeongnam, and Jeonnam Provinces in Korea is more than twice the national average. This study aimed to examine whether demographic and lifestyle characteristics are associated with HCV infection in these areas. Methods: A case control study was performed at three study hospitals. HCV cases were matched with two controls for sex and age. Patient controls were selected from non-HCV patients at the same hospital. Healthy controls were subjects participating in medical checkups. Conditional logistic regression models were used. Results: A total of 234 matchedcase and patient- and healthy-control pairs were analyzed. The significant risk factors for both controls were sharing razors (adjusted odds ratio [aOR], 2.39 and 3.29, respectively) and having more than four lifetime sexual partners (aOR, 2.15 and 6.89, respectively). Contact dockworkers (aOR, 1.91) and tattoos (aOR, 2.20) were significant risk factors for the patient controls. Transfusion (aOR, 5.38), a bloody operation (aOR, 5.02), acupuncture (aOR, 2.08), and piercing (aOR, 5.95) were significant risk factors for the healthy controls. Needle stick injuries and intravenous drug abuse were significant in the univariate analysis. Conclusions: More education concerning the dangers of sharing razors, tattoos and piercings is required to prevent $\mathrm{HCV}$ infection. More attention should be paid to needle stick injuries in hospitals and the community. (Gut Liver 2016;10:126-132)

Key Words: Hepacivirus; Case-control studies; Risk factors; Korea

\section{INTRODUCTION}

The hepatitis C virus (HCV) was discovered relatively recently. $\mathrm{HCV}$ infection results in chronic hepatitis at a higher rate than that of hepatitis B virus (HBV) infection. When HCV infection proceeds to chronic infection, it can cause cirrhosis, hepatic decompensation, and hepatocellular carcinoma. ${ }^{1}$ HCV infection is difficult to prevent, as there is presently no vaccine for it.

The worldwide prevalence of HCV is approximately 3\%; however, in Asia, the prevalence is reportedly approximately $1 \%$ to $2 \%$ when some countries are excluded. In Korea, the prevalence of HCV is reportedly $0.41 \%$ to $2.1 \%$ and differs depending on the target group, age, and region. ${ }^{3}$ A recent large-scale study of participants at medical checkups reported an age-, sex-, and areaadjusted anti-HCV antibody positive rate of $0.78 \%$ in adults. In contrast, the HCV prevalence rates for the city of Busan and the province of Jeonnam were 1.53\% and 2.07\%, respectively, more than twice the national average. ${ }^{4}$ Similarly, in research using the Korea National Health Insurance data, Busan showed highest prevalence of HCV, followed by the provinces of Jeonnam and Gyeongnam.

Intravenous (IV) drug abuse is the greatest risk factor for HCV infection in Korea. The prevalence of HCV in IV drug abusers has been reported to be $48.4 \% .{ }^{6}$ Other risk factors for HCV infection include surgery, ${ }^{7}$ tattoo, ${ }^{8}$ body piercing, ${ }^{9}$ and acupuncture. ${ }^{10}$ However, little is known as to how these risk factors affect HCV prevalence in regions of Korea where HCV infection is more highly prevalent. Thus, we performed a case-control study to identify the risk factors for HCV infection in the regions of Korea with the highest prevalence of HCV, which are Busan and

Correspondence to: Moran Ki

Department of Cancer Control and Policy, National Cancer Center, 323 Ilsan-ro, Ilsandong-gu, Goyang 10408, Korea

Tel: +82-31-920-2736, Fax: +82-50-4069-4908, E-mail: moranki@naver.com

Received on October 16, 2014. Revised on January 17, 2015. Accepted on February 4, 2015. Published online August 11, 2015 pISSN 1976-2283 eISSN 2005-1212 http://dx.doi.org/10.5009/gnl14403

(a) This is an Open Access article distributed under the terms of the Creative Commons Attribution Non-Commercial License (http://creativecommons.org/licenses/by-nc/4.0) which permits unrestricted non-commercial use, distribution, and reproduction in any medium, provided the original work is properly cited. 
the provinces of Gyeongnam and Jeonnam.

\section{MATERIALS AND METHODS}

The HCV antibody positive rate in the general adult population of Korea is known to be $1 \%$ to $3 \%$. The prevalence of clinical patients is lower than the antibody positive rate. Thus, a hospital-based case-control study was performed at three study hospitals.

\section{Study subjects}

Patients receiving treatment for HCV infection in the gastroenterology departments of the study hospitals were included in the case group. Individuals who were hepatitis B surface antigen and hepatitis $C$ antibody negative were included in the control group. When individuals were positive for hepatitis B surface antibody, those who had a history of vaccination for HBV and no history of HBV infection were included in the control group. The control group was categorized into two groups: healthycontrol and patient-control. The healthy-control group consisted of participants recruited at a medical checkup, whereas, the patient-control group consisted of non-HCV patients who visited the gastroenterology departments at the hospitals where cases were selected. Controls were matched to cases for sex and age within 5 years.

\section{Study questionnaires}

Questionnaires based on the questionnaires developed for a cohort study of HCV patients by the Korea Centers for Disease Control and Prevention were developed that included questions that were in alignment with the objective of the casecontrol study. The questionnaire consisted of questions about participant's demographics, including occupational history, residence, and family history, as well as other related factors including medical history, invasive nonmedical behavior, personal hygiene, IV drug abuse, and sexual history. Face-to-face interviews were performed by trained researchers. Interviewees answered personal questions, including those about IV drug abuse, imprisonment history, or sexual experiences, in solitude. For the IV drug abuse, the exact question was "Have you ever had an IV injection (narcotics, Nubain, or psychoactive drugs) not for treatment?"

\section{Sample size}

Sample size was calculated using Open Epi ${ }^{11}$ with type I error set at 0.05 and type II error set at 0.20. Using the rates of moxibustion, tattoos, and IV drug abuse from Korea Centers for Disease Control and Prevention study from 2012 as a guide, 60 to 100 matched pairs from each region was the target sample size. The final sample size was 234 pairs, with 64 pairs from Busan, 109 pairs from Gyeongnam province, and 61 pairs from Jeonnam province.

\section{Statistical analyses}

Conditional logistic regression analysis was performed to compare cases and controls. Odds ratios, 95\% confidence intervals, and p-values were calculated. Nonresponses were not included in the statistical analyses. Variables that were statistically significant by univariate analyses were included in multiple conditional logistic regression models as independent variables. For variables that showed multicollinearity, only one variable was included in the model. Variables that occurred at too low a frequency to observe statistically significant differences were excluded from the model.

\section{Ethics}

The study was performed at three teaching hospitals in the three regions and was approved by the Institutional Review Board of each of the hospitals in 2013. Written informed consent was obtained from both cases and controls.

\section{RESULTS}

\section{General characteristics of study subjects}

Research subjects were matched by sex and age within 5 years. The ratio of men to women and the proportions by age were similar between cases and controls. Specifically, the proportion of men was 54.3\%. The most common age groups were the 50-59 years old and 60-69 years old age groups, each accounting for approximately $30 \%$ of participants. The next most common age groups were the 70 years and older group and the 40-49 years old group. Subjects in the 20-39 years old group accounted for approximately $5 \%$ of the study population. The proportion of college graduates was significantly higher in the healthy-control group than in the patient-control and case groups (Table 1).

\section{Risk factors for HCV infection}

Marine related occupations including fishery workers, sailors, and dockworkers were more common in the case group (odds ratio [OR], 8.67 for healthy-controls) than in the control group. In addition, in the case group, the rates of history of living in an area with high prevalence of HCV (OR, 1.82 for patient-controls and OR, 1.78 for healthy-controls), history of living or working near the sea (OR, 1.69 for patient-controls and OR, 4.68 for healthy-controls), and history of contact dockworker (OR, 1.81 for patient-controls and $\mathrm{OR}, 2.00$ for healthy-controls) were significantly higher.

There was no significant difference in history of gastroscopy, colonoscopy, or blood dialysis between the groups; however, experiences of transfusion (OR, 5.64) and invasive treatments such as surgery $(\mathrm{OR}, 3.84)$ and bloody operation $(\mathrm{OR}, 6.50)$ were significantly higher in the case group than the healthy-control group. In addition, needle stick injury (OR, 9.00 for patient- 
Table 1. General Characteristics of Study Subjects

\begin{tabular}{|c|c|c|c|c|}
\hline Variable & $\begin{array}{c}\text { Cases } \\
(\mathrm{n}=234)\end{array}$ & $\begin{array}{l}\text { Patient-controls } \\
\quad(n=234)\end{array}$ & $\begin{array}{l}\text { Healthy-controls } \\
\qquad(\mathrm{n}=234)\end{array}$ & $\mathrm{p}$-value \\
\hline \multicolumn{5}{|l|}{ Sex } \\
\hline Male & 127 (54.3) & $127(54.3)$ & $127(54.3)$ & 1.000 \\
\hline Female & 107 (45.7) & $107(45.7)$ & $107(45.7)$ & \\
\hline \multicolumn{5}{|l|}{ Age group } \\
\hline $20-39$ & $12(5.1)$ & $14(6.0)$ & $11(4.7)$ & 0.858 \\
\hline $40-49$ & 31 (13.2) & 37 (15.8) & 44 (18.8) & \\
\hline $50-59$ & 73 (31.2) & 75 (32.0) & 73 (31.2) & \\
\hline $60-69$ & $75(32.1)$ & $69(29.5)$ & $72(30.8)$ & \\
\hline$\geq 70$ & 43 (18.4) & 39 (16.7) & $34(14.5)$ & \\
\hline \multicolumn{5}{|l|}{ Education } \\
\hline$<$ High school & 111 (49.6) & $129(56.6)$ & $56(24.0)$ & $<0.001$ \\
\hline High school & 80 (35.7) & $55(24.1)$ & 76 (32.6) & \\
\hline$\geq$ College & 33 (14.7) & 44 (19.3) & $101(43.4)$ & \\
\hline \multicolumn{5}{|c|}{ Area of study hospital } \\
\hline Busan & 64 (27.3) & 64 (27.3) & 64 (27.3) & 1.000 \\
\hline Gyeongnam & $109(46.6)$ & $109(46.6)$ & $109(46.6)$ & \\
\hline Jeonnam & $61(26.1)$ & $61(26.1)$ & $61(26.1)$ & \\
\hline
\end{tabular}

Data are presented as number (\%).

controls and OR, 18.00 for healthy-controls), acupuncture (OR, 1.96 for patient-controls and OR, 3.42 for healthy-controls), moxibustion (OR, 1.64 for patient-controls and OR, 2.23 for healthy-controls), and phlebotomy (OR, 1.71 for patient-controls and $\mathrm{OR}, 2.35$ for healthy-controls) were significantly higher for the case group than for the patient-control and healthy-control groups.

Among invasive nonmedical behaviors, sharing razors (OR, 2.67 for patient-controls and OR, 9.23 for healthy-controls), using other people's razors (OR, 2.58 for patient-controls, and OR, 4.47 for healthy-controls), tattoos (OR, 2.05 for patient-controls and OR, 2.29 for healthy-controls), body piercing (OR, 2.46 for patient-controls and OR, 4.91 for healthy-controls), and nail care in a shop (OR, 2.75 for patient-controls and OR, 2.22 for healthy-controls) were significant risk factors when the control group was compared to both the patient-control and healthycontrol groups. In contrast, dental treatment by an unlicensed individual (OR, 2.44) and IV drug abuse (OR, 3.75 for healthycontrols) were significant risk factor only when the case group was compared to the healthy-controls.

More than four lifetime sexual partners (OR, 2.00 for patientcontrols and OR, 7.00 for healthy-controls) and history of imprisonment (OR, 2.08 for patient-controls and OR, 15.50 for healthy-controls) were significant factors for both the patientcontrol and healthy-control groups, whereas condom use was not a significant risk factor (Table 2).

Using multiple conditional logistic regression models, separate analyses were performed for both control groups that included all of the significant variables from the univariate analyses. However, number of control for needle stick injury and IV drug abuse was too small, the variables were not included in the multiple model. Using backward methods, the final model included only significant variables. When the case group was compared to the patient-control group, contact dockworker (adjusted OR [aOR], 1.91; 95\% confidence interval [CI], 1.19 to 3.05), using razors of others (aOR, 2.39; 95\% CI, 1.34 to 4.26), tattoo (aOR, 2.20; $95 \%$ CI, 1.17 to 4.17 ), and more than four lifetime sexual partner (aOR, 2.15; 95\% CI, 1.02 to 4.50) were significant. Similarly, two of these four factors were significant when the case group was compared with the healthy-controls group (using razors of others: aOR, 3.29, 95\% CI, 1.49 to 7.28; and more than 4 lifetime sexual partner: aOR, 6.89, 95\% CI, 1.64 to 28.99). In addition, when the case group was compared to the healthy-controls group, significant risk factors for HCV infection included transfusion (aOR, 5.38; 95\% CI, 2.06 to 14.05), bloody operation (aOR, 5.02; 95\% CI, 1.34 to 18.83), acupuncture (aOR, 2.08; 95\% CI, 1.01 to 4.32 ), and body piercing (aOR, 5.95; 95\% CI, 2.08 to 17.01). While history of living in an area of high prevalence of HCV, history of moxibustion, history of phlebotomy, history of nail care in a shop and history of imprisonment were included in the models, the variables did not show significant aOR for either control group (Table 3).

\section{DISCUSSION}

The prevalence of HCV infection in Korea is not high when 
Table 2. Crude Odds Ratios for the Association of Various Factors with Hepatitis C Virus (HCV) Infection in Areas of High Prevalence of HCV Infection in the Republic of Korea

\begin{tabular}{|c|c|c|c|c|c|c|c|}
\hline \multirow{2}{*}{ Variable } & \multirow{2}{*}{$\begin{array}{c}\text { Cases } \\
(\mathrm{n}=234)\end{array}$} & \multicolumn{2}{|c|}{ Controls } & \multicolumn{2}{|c|}{$\begin{array}{c}\text { Case vs } \\
\text { patients-control }\end{array}$} & \multicolumn{2}{|c|}{$\begin{array}{c}\text { Case vs } \\
\text { healthy-control }\end{array}$} \\
\hline & & $\begin{array}{l}\text { Patient-controls } \\
\qquad(\mathrm{n}=234)\end{array}$ & $\begin{array}{l}\text { Healthy-controls } \\
\qquad(\mathrm{n}=234)\end{array}$ & OR & $95 \%$ CI & OR & $95 \% \mathrm{CI}$ \\
\hline Marine occupations* & $26(11.1)$ & $16(6.8)$ & $3(1.3)$ & 1.77 & $0.90-3.49$ & 8.67 & $2.62-28.63$ \\
\hline History of living in HCV high-prevalence area $^{\dagger}$ & 79 (33.8) & $51(21.8)$ & $50(21.4)$ & 1.82 & $1.20-2.77$ & 1.78 & $1.19-2.67$ \\
\hline History of living or working near the sea & $139(59.4)$ & $110(47.0)$ & $57(24.4)$ & 1.69 & $1.15-2.48$ & 4.68 & $2.96-7.42$ \\
\hline Contact dockworker & $100(41.7)$ & $71(30.3)$ & $64(27.4)$ & 1.81 & $1.20-2.71$ & 2.00 & $1.34-2.98$ \\
\hline Gastroscopy & $216(92.3)$ & $214(91.5)$ & $222(94.9)$ & 1.15 & $0.55-2.43$ & 0.56 & $0.25-1.27$ \\
\hline Colonoscopy & $135(57.7)$ & $116(49.6)$ & $153(65.4)$ & 1.44 & $0.98-2.13$ & 0.70 & $0.47-1.04$ \\
\hline Transplantation & $1(0.4)$ & 0 & 0 & - & - & - & - \\
\hline Blood dialysis & $3(1.3)$ & $5(2.1)$ & $1(0.4)$ & 0.50 & $0.09-2.73$ & 3.00 & $0.31-28.84$ \\
\hline Transfusion & $64(27.4)$ & 78 (33.3) & $13(5.6)$ & 0.76 & $0.51-1.12$ & 5.64 & $2.97-10.70$ \\
\hline Transfusion (before 1990) $^{\ddagger}$ & $24(10.3)$ & $16(6.8)$ & $6(2.6)$ & 2.00 & $0.50-8.00$ & 4.80 & $1.83-12.58$ \\
\hline Surgery & $152(65.0)$ & $144(61.5)$ & $81(34.6)$ & 1.15 & $0.78-1.70$ & 3.84 & $2.47-5.96$ \\
\hline Bloody operation & $40(17.1)$ & $48(20.5)$ & $7(3.0)$ & 0.80 & $0.50-1.27$ & 6.50 & $2.75-15.35$ \\
\hline Needle stick injury & $18(7.7)$ & $2(0.9)$ & $1(0.4)$ & 9.00 & $2.09-38.79$ & 18.00 & $2.40-134.83$ \\
\hline Acupuncture & $193(82.5)$ & $172(73.5)$ & $135(57.7)$ & 1.96 & $1.17-3.27$ & 3.42 & $2.17-5.39$ \\
\hline Moxibustion & $114(48.7)$ & $87(37.2)$ & $75(32.1)$ & 1.64 & $1.14-2.38$ & 2.23 & $1.46-3.40$ \\
\hline Phlebotomy & $106(45.3)$ & 78 (33.3) & $59(25.2)$ & 1.71 & $1.16-2.51$ & 2.35 & $1.58-3.52$ \\
\hline Sharing razors & $140(59.8)$ & $112(47.9)$ & $26(11.1)$ & 2.67 & $1.55-4.58$ & 9.23 & $5.21-16.36$ \\
\hline Using other's razors & $104(44.4)$ & 74 (31.6) & 45 (19.2) & 2.58 & $1.52-4.38$ & 4.47 & $2.64-7.56$ \\
\hline Using other's toothbrushes & $43(48.4)$ & $34(14.5)$ & $36(15.4)$ & 1.36 & $0.81-2.28$ & 1.21 & $0.74-1.97$ \\
\hline Tattoo & $75(32.1)$ & $55(23.5)$ & $48(20.5)$ & 2.05 & $1.19-3.55$ & 2.29 & $1.37-3.82$ \\
\hline Body piercing & 67 (28.6) & $51(21.8)$ & $24(10.3)$ & 2.46 & $1.22-4.95$ & 4.91 & $2.57-9.39$ \\
\hline Nail care in a shop & $24(10.3)$ & $10(4.3)$ & $13(5.6)$ & 2.75 & $1.22-6.18$ & 2.22 & $1.01-4.88$ \\
\hline Cosmetic surgery by an unlicensed person & $4(1.7)$ & $1(0.4)$ & $1(0.4)$ & 4.00 & $0.45-35.79$ & 3.00 & $0.31-28.84$ \\
\hline Dental treatment by an unlicensed person & $24(10.3)$ & $28(12.0)$ & $9(3.8)$ & 0.88 & $0.49-1.57$ & 2.44 & $1.13-5.31$ \\
\hline IV drug abuse & $15(6.4)$ & 0 & $4(1.7)$ & - & - & 3.75 & $1.25-11.30$ \\
\hline$\geq 4$ lifetime sexual partners & $38(16.2)$ & $24(10.3)$ & $8(3.4)$ & 2.00 & $1.05-3.80$ & 7.00 & $2.74-17.87$ \\
\hline Sexual experience with foreigner & $9(3.8)$ & $6(2.6)$ & $3(1.3)$ & 1.80 & $0.60-5.37$ & 2.00 & $0.37-10.92$ \\
\hline Condom use & $20(8.5)$ & $28(12.0)$ & $16(6.8)$ & 0.64 & $0.33-1.24$ & 1.27 & $0.64-2.49$ \\
\hline Imprisonment & $31(13.2)$ & $17(7.3)$ & $2(0.9)$ & 2.08 & $1.07-4.03$ & 15.50 & $3.71-64.76$ \\
\hline
\end{tabular}

Data are presented as number (\%).

OR, odds ratio; CI, confidence interval; IV, intravenous.

*Fishers, sailors, and dockworkers; 'Busan: Jung-gu, Seo-gu; Gyeongnam: Namhae, Sacheon, Geoje, Tongyeong; Jeonnam: Mokpo, Shinan, and Jindo; ${ }^{\ddagger}$ Blood transfusions before 1990 were compared to patients who did not receive transfusions.

compared to other countries; however it is rising. In addition, liver cancer incidence in Korea is among the highest in the world. The prevalence of HCV infection in Busan and the provinces of Gyeongnam and Jeonnam in Korea is more than twice that of the national average prevalence of HCV infection in Korea. $^{5}$ To identify risk factors for HCV infection in these areas of high prevalence of HCV, we performed a case-control study and found that using razors of others and more than four lifetime sexual partner are significant risk factors for HCV infection in both patient and healthy controls. Tattoo, and contact dock- worker are significant when it compared to patient controls. In comparison with healthy controls, education, transfusion, bloody operation, acupuncture, and body piercing are also significant risk factors.

Using other people's razors or sharing razors can be a risk factor for infections transmitted by blood, including HCV infection, as the users can be exposed to contaminated blood. In this study, both using other people's razors and sharing razors were significant risk factors in univariate analysis. These two variables are highly correlated; using other people's razors was in- 
Table 3. Conditional Logistic Regression Analysis for Hepatitis C Virus (HCV) Infection in Areas of High Prevalence of HCV Infection in the Republic of Korea

\begin{tabular}{lcc}
\hline \multicolumn{1}{c}{ Variable/reference } & \multicolumn{2}{c}{ Adjusted OR (95\% CI) } \\
\cline { 2 - 3 } & Case vs patients-control & Case vs healthy-control \\
\hline Education & - & $11.69(4.27-31.99)$ \\
$\quad<$ High school/college & - & $3.76(1.69-8.35)$ \\
$\quad$ High school/college & $1.91(1.19-3.05)$ & $5.38(2.06-14.05)$ \\
Contact dockworker & - & $5.02(1.34-18.83)$ \\
Transfusion & - & $2.08(1.01-4.32)$ \\
Bloody operation & - & $3.29(1.49-7.28)$ \\
Acupuncture & $2.39(1.34-4.26)$ & $5.95(2.08-17.01)$ \\
Using other's razors & - & - \\
Body piercing & $2.20(1.17-4.17)$ & $6.89(1.64-28.99)$ \\
Tattoo & $2.15(1.02-4.50)$ & \\
Lifetime sexual partner $\geq 4 /<4$ & .
\end{tabular}

The variables history of living in an area of high prevalence of HCV, history of moxibustion, history of phlebotomy, history of nail care in a shop and imprisonment were included in the models. The variables did not show significant adjusted OR for either control group.

$\mathrm{OR}$, odds ratio; CI, confidence interval.

cluded in multiple analyses. Similarly, in Chinese blood donors, razor sharing increases the risk of HCV infection as much as 29 times (95\% CI, 12.89 to 66.00). ${ }^{12}$ In addition, in individuals infected with human immunodeficiency virus (HIV), razor sharing increases the risk of HCV infection 4.81 times (95\% CI, 1.84 to 12.55). ${ }^{13}$

Sexual history correlated with HCV infection in both control groups when study subjects had more than four sexual partners. In a similar study in Korea where the control group was chosen from chronic liver disease patients in Korea, a lifetime history of four or more sexual partners had an OR of 3.19 (95\% CI, 1.58 to 6.42) for HCV infection, ${ }^{14}$ whereas three sexual partners had a nonsignificant OR of 1.37 (95\% CI, 0.86 to 2.17). ${ }^{15}$ Thus, the number of sexual partners is important and having more than four sexual partners is thought to be a risk factor for HCV infection.

Tattoos and piercings have been increasing, the risk of HCV are not confirmed. One meta-analysis reported the risk of HCV infection is significant, when tattoos are applied in prison settings or by friends (aOR, 2.0 to 3.6). ${ }^{9}$ However, recent metaanalysis reported tattoo as the significant risk factor for $\mathrm{HCV}$ infection (OR, 2.338; 95\% CI, 1.922 to 2.845$){ }^{8}$ In our study, tattoo and body piercing were identified as risk factors for patientcontrol and healthy-control, respectively. In Korea, currently, there are no laws regulating the tattoo industry, and only licensed health care professionals such as medical doctors, nurses, and Oriental medicine practitioners can legally pierce a person's skin with a needle. However over 90\% of tattoo recipients are tattooed by tattoo-artists. This is illegal at present. So tattoo shops and tattoo-artists are not monitored by the government and hygiene controls are not applied properly, and for these reasons, the tattoo recipients are vulnerable to infection. In The Netherlands, one study reported the people with multiple tattoos and/or piercings are not at increased risk for hepatitis B or $\mathrm{C}$ virus infection; it might be due to the introduction of hygiene guidelines for tattoo and piercing shops. ${ }^{16}$

In this study, transfusion, bloody operation, acupuncture, body piercing, and education were significant risk factors for HCV infection when the case group was compared to the healthy-control group. In contrast, these variables were not significant risk factors when the case group was compared to the patient-controls group. Transfusion and bloody operation is thought to be risk factors for diseases transmitted by blood in general rather than specific risk factors for HCV infection, which may explain why our results do not correspond with what has been found previously for the correlation of HCV and medical treatment. ${ }^{3,7,14,17,18}$

While it has been reported previously that there is no association between acupuncture and HCV infection, ${ }^{15,18}$ a significant OR of 2.2 (95\% CI, 1.0 to 4.7) has been found for a history of 10 or more acupuncture sessions. ${ }^{7}$ In our study, acupuncture was significant risk factor in univariate analysis for both control groups, and it was significant in multiple analysis for the healthy-control group.

Imprisonment is known to be a risk factor for $\mathrm{HBV}, \mathrm{HCV}$, and HIV infection. In our study, it was only significant in univariate analysis. In other studies, the incidence of HCV in prisoners has been reported to 14.08 per 100 person year (95\% CI, 9.96 to 19.32). ${ }^{19}$ In addition, if a person has a history of imprisonment, the risk of HCV infection has been reported to be increased 2.49 times (95\% CI, 1.40 to 4.42$){ }^{20}$

Needle stick injury is known to be a risk factor for the trans- 
mission of blood-borne diseases, including HCV infection. ${ }^{21,22}$ Specifically, it has been previously reported to be a risk factor for health care providers; ${ }^{23,24}$ however, there have also been cases reported of blood-borne disease infection by needle stick injury in communities. ${ }^{25}$ In our study, needle stick injury showed significant ORs in both control groups; it was not be included in the multiple analyses as there was only one person in the healthy-control group. IV drug abuse was also identified as a significant risk factor for HCV infection, similar to what has been reported previously. ${ }^{15,17,26-28}$ However, IV drug abuse also could not be included in the multiple conditional logistic regression analysis as there were no IV drug abusers in the patientcontrol group.

In this study, ORs were higher for the healthy-control group compared to the case group than for the patient-control group compared to the case group. Specifically, medical treatment variables such as transfusion, bloody operation, and dental treatment by an unlicensed person, and education were not significant risk factors when the patient-control group was compared by univariate analysis to the cases group, whereas the associations were significant when the healthy-control group was compared to the case group. Thus, it is possible that these variables are not specific risk factors for HCV infection. In order to identify specific risk factors for HCV infection using a casecontrol study, the controls also should be chosen from patientcontrols that have a similar disease status.

In summary, we found that factors including using other's razors, tattoo, and body piercing were risk factors for HCV infection, which are associations that have not been observed previously in studies in Korea. Specifically, adjusted ORs for using other's razors was observed to be significant risk factor for both control groups. Thus, to help prevent HCV infection in Korea, public awareness about not using other's razors, and dangers of tattoo and body piercing should be promoted.

\section{CONFLICTS OF INTEREST}

No potential conflict of interest relevant to this article was reported.

\section{ACKNOWLEDGEMENTS}

This study was supported by the Research Program funded by the Korea Centers for Disease Control and Prevention (fund code: 213E2400100).

\section{REFERENCES}

1. Lauer GM, Walker BD. Hepatitis C virus infection. N Engl J Med 2001;345:41-52.

2. Sievert W, Altraif I, Razavi HA, et al. A systematic review of hepatitis C virus epidemiology in Asia, Australia and Egypt. Liver Int
2011;31 Suppl 2:61-80.

3. Shin HR. Epidemiology of hepatitis C virus in Korea. Intervirology 2006;49:18-22.

4. Kim do Y, Kim IH, Jeong SH, et al. A nationwide seroepidemiology of hepatitis C virus infection in South Korea. Liver Int 2013;33:586-594.

5. Kwon GY, Lee H, Gwack J, Lee SW, Ki M, Youn SK. Regional distribution of hepatitis $\mathrm{C}$ virus infection in the Republic of Korea, 2007-2011. Gut Liver 2014;8:428-432.

6. Min JA, Yoon Y, Lee HJ, et al. Prevalence and associated clinical characteristics of hepatitis B, C, and HIV infections among injecting drug users in Korea. J Med Virol 2013;85:575-582.

7. Shin HR, Kim JY, Ohno T, et al. Prevalence and risk factors of hepatitis C virus infection among Koreans in rural area of Korea. Hepatol Res 2000;17:185-196.

8. El-Ghitany EM, Abdel Wahab MM, Abd El-Wahab EW, Hassouna S, Farghaly AG. A comprehensive hepatitis $C$ virus risk factors meta-analysis (1989-2013): do they differ in Egypt? Liver Int 2015;35:489-501.

9. Tohme RA, Holmberg SD. Transmission of hepatitis C virus infection through tattooing and piercing: a critical review. Clin Infect Dis 2012;54:1167-1178.

10. Shin HR, Kim JY, Kim JI, et al. Hepatitis B and C virus prevalence in a rural area of South Korea: the role of acupuncture. Br J Cancer 2002;87:314-318.

11. Kelsey JL. Methods in observational epidemiology. 2nd ed. New York: Oxford University Press, 1996.

12. He Y, Zhang J, Zhong L, et al. Prevalence of and risk factors for hepatitis $C$ virus infection among blood donors in Chengdu, China. J Med Virol 2011;83:616-621.

13. Alipour A, Rezaianzadeh A, Hasanzadeh J, Rajaeefard A, Davarpanah MA. Sexual transmission of hepatitis $C$ virus between HIV infected subjects and their main heterosexual partners. Hepat Mon 2013;13:e13593.

14. Kim JY, Cho J, Hwang SH, et al. Behavioral and healthcare-associated risk factors for chronic hepatitis C virus infection in Korea. J Korean Med Sci 2012;27:1371-1377.

15. Seong MH, Kil H, Kim YS, et al. Clinical and epidemiological features of hepatitis C virus infection in South Korea: a prospective, multicenter cohort study. J Med Virol 2013;85:1724-1733.

16. Urbanus AT, van den Hoek A, Boonstra A, et al. People with multiple tattoos and/or piercings are not at increased risk for HBV or HCV in The Netherlands. PLoS One 2011;6:e24736.

17. Memon MI, Memon MA. Hepatitis C: an epidemiological review. J Viral Hepat 2002;9:84-100.

18. Kim YS, Ahn YO, Kim DW. A case-control study on the risk factors of hepatitis $\mathrm{C}$ virus infection among Koreans. J Korean Med Sci 1996;11:38-43.

19. Luciani F, Bretaña NA, Teutsch S, et al. A prospective study of hepatitis C incidence in Australian prisoners. Addiction 2014;109:1695-1706.

20. Nokhodian Z, Meshkati M, Adibi P, et al. Hepatitis C among intra- 
venous drug users in Isfahan, Iran: a study of seroprevalence and risk factors. Int J Prev Med 2012;3(Suppl 1):S131-S138.

21. Ridzon R, Gallagher K, Ciesielski C, et al. Simultaneous transmission of human immunodeficiency virus and hepatitis $\mathrm{C}$ virus from a needle-stick injury. N Engl J Med 1997;336:919-922.

22. Kogure T, Ueno Y, Kanno N, et al. Sustained viral response of a case of acute hepatitis $C$ virus infection via needle-stick injury. World J Gastroenterol 2006;12:4757-4760.

23. Kiyosawa K, Sodeyama T, Tanaka E, et al. Hepatitis C in hospital employees with needlestick injuries. Ann Intern Med 1991;115: 367-369.

24. Marranconi F, Mecenero V, Pellizzer GP, et al. HCV infection after accidental needlestick injury in health-care workers. Infection
1992;20:111.

25. Haber PS, Young MM, Dorrington L, et al. Transmission of hepatitis $\mathrm{C}$ virus by needle-stick injury in community settings. J Gastroenterol Hepatol 2007;22:1882-1885.

26. Bruandet A, Lucidarme D, Decoster A, et al. Incidence and risk factors of HCV infection in a cohort of intravenous drug users in the North and East of France. Rev Epidemiol Sante Publique 2006; 54 Spec No 1:1S15-1S22.

27. Kwon JH, Bae SH. Current status and clinical course of hepatitis C virus in Korea. Korean J Gastroenterol 2008;51:360-367.

28. Hutchinson SJ, Roy KM, Wadd S, et al. Hepatitis C virus infection in Scotland: epidemiological review and public health challenges. Scott Med J 2006;51:8-15. 